\title{
The Effect of Exclusive Breastfeeding on Wasting in Children Under Five: A Meta-Analysis Study
}

\author{
Amallia Wijiwinarsih"), Tri Nugraha Susilawati'), Bhisma Murti1) \\ 1)Masters Program in Public Health, Universitas Sebelas Maret \\ ${ }^{2)}$ Faculty of Medicine, Universitas Sebelas Maret
}

\begin{abstract}
Background: Wasting is a form of malnutrition that has become a serious global health problem for the past few decades. Global prevalence of wasting is reported to reach 52 million or $7.7 \%$ of the under-fives. Global coverage of exclusive breastfeeding was still as low as $40 \%$. The purpose of this study was to due a meta-analysis on the effect of exclusive breastfeeding on wasting in children under five.

Subjects and Method: This was a meta-analysis study conducted from PubMed, SCOPUS, DOAJ, BASE, EBSCO, Emerald, ProQuest, ScienceDirect, ResearchGate, and Google Scholar databases. This study sought a systematic review with an observational study design and multivariate adjusted odds ratio (AOR) analysis. Wasting was defined as weight for height (WHZ) Z score <-2. The data were analyzed by RevMan 5 meta-analysis program with a fixed effect and random effect analysis model.

Results: There were 13 articles included in this study. Based on 3 study design, exclusive breastfeeding could prevent the risk of wasting in children under five with each meta-analysis result from a cross-sectional study 0.42 times ( $\mathrm{OR}=0.42 ; 95 \% \mathrm{CI}=0.28$ to $0.62 ; \mathrm{p}<0.001$ ), casecontrol studies 0.38 times $(\mathrm{OR}=0.38 ; 95 \% \mathrm{CI}=0.27$ to $0.54 ; \mathrm{p}<0.001)$, and cohort studies 0.75 times (OR $=0.75 ; 95 \% \mathrm{CI}=0.55$ to $1.04 ; \mathrm{p}=0.08$ ). There was no publication bias in the results of the cross-sectional and case-control study meta-analysis, but there was in the results of the metaanalysis of the cohort study.
\end{abstract}

Conclusion: Exclusive breastfeeding can prevent wasting in children under five.

Keywords: exclusive breastfeeding, wasting, observational study

\section{Correspondence:}

Amallia Wijiwinarsih.Masters Program in Public Health, Universitas Sebelas Maret. Jl. Ir, Sutami 36A, Surakarta, Central Java 57126.Email: amalliawijiwinarsih@gmail.com. Mobile: 0857261706.

\section{BACKGROUND}

Wasting is a form of malnutrition which has become a serious problem for global public health over the past few decades, especially in developing countries (Tariku et al., 2016; Abebe et al., 2017). The United Nations (UN) formulated the second goal of the Sustainable Development Goals (SDGs) to end all forms of malnutrition in 2030 including achieving international targets in 2025, one of them is to reduce the prevalence of wasting (World Health Organization, 2018).
Wasting is a condition in which a toddler has a lower body weight compared to his height, in other words if a toddler's weight is in a $\mathrm{Z}$ score $<-2 \mathrm{SD}$ then the toddler is experiencing wasting (Black et al., 2013; Bentley et al ., 2015; Aguayo et al 2017).

Global prevalence of wasting is reported to reach 52 million or $7.7 \%$ of under-fives experiencing wasting. Based on data from UNICEF, WHO and the World Bank the prevalence of continental based wasting in 2017 is presented as follows; the Asian continent of 35.9 millions, the 
continent of Africa; 14 million, and the continent of America; 1 million. The Asian continent is the continent with the highest prevalence of wasting in the world, thus wasting it into an unresolved toddler health problem in Asia (WHO, 2018).

Every year the under-five mortality rate is associated with wasting events. The study reported that wasting was responsible for 21 million or $21 \%$ of deaths of children under 5 years and 91 million or $21 \%$ adjusted for life years (DALYs) in children under 5 years old, $7 \%$ of total global DALY (Black et al. , 2008).

Some research reports that risky wasting increases the incidence of diarrhea, acute tract infections, chronic diseases, brain damage, inhibiting physical, intellectual, mental, intelligence, and decreasing toddler productivity (Asfaw et al., 2015; Bentley et al., 2015; Briend, Khara and Dolan, 2015; Fekadu et al., 2015; Abebe et al., 2017b; Aguayo et al., 2017).

Exclusive breastfeeding can prevent wasting in infants. Children under five years old who are not given exclusive breastfeeding have a greater risk of wasting when compared to children who are exclusively breastfed (Abebe et al., 2017) Gautam et al. (2017) (Asfaw et al., 2015).

However, global exclusive breastfeeding coverage is still very low, with only $40 \%$ of babies breastfed during the first 6 months of life (UNICEF, 2018). The practice of non-exclusive breastfeeding is estimated to account for more than $11 \%$ of deaths of children under five years (Black et al., 2013).

Many studies have shown that children who are not given exclusive breastfeeding have a greater risk of wasting when compared to toddlers who are given exclusive breastfeeding for 6 months. So this study aims to analyze the effect of exclusive breastfeeding on wasting events in infants.

\section{SUBJECTS AND METHOD \\ 1. Study Design}

This research uses meta-analysis method and systematic review. Systematic database searches from several indexes including: PubMed, SCOPUS, DOAJ, BASE, EBSCO, Emerald, ProQuest, ScienceDirect, ResearchGate and Google Scholar. The search uses the keywords "stuntingand exclusive breastfeeding AND multivariate", "wasting AND exclusive breastfeeding AND multivariate", and "underweight AND exclusive breastfeeding AND multivariate".

\section{Inclusion Criteria}

The inclusion criteria of this study used an obsessive study design with multivariate adjusted odds ratio analysis that could control confounding factors with exclusive breastfeeding interventions in infants. This study reports articles published from 20082018.

\section{Exclusion Criteria}

The exclusion criteria in this study were studies conducted with RCTs, case controls, quasi-experimental, study protocols or pilot studies. Articles published in Arabic, Spanish, Chinese, French, and Russian are also research exclusion criteria.

\section{Operational definition of variables}

Wasting is a condition in which a toddler has a lower body weight compared to his height, in other words if a children weight is in a $\mathrm{Z}$ score <-2 SD then the toddler is experiencing wasting (Black et al., 2013; Bentley et al ., 2015; Aguayo et al 2017). Meanwhile, exclusive breastfeeding is breastfeeding for the first 6 months of life without any additional food and use categorical data and published article instruments.

\section{Data Analysis}

The RevMan 5 meta-analysis program was used in this study and the analysis included random effects and multivariate. 


\section{RESULTS}

Article searches are carried out through a journal database which includes: PubMed, SCOPUS, DOAJ, BASE, EBSCO, Emerald, ProQuest, ScienceDirect, ResearchGate and Google Scholar by using search keywords "stunting AND exclusive breastfeeding AND multivariate", "wasting AND exclusive breastfeeding AND multivariate", and "underweight AND exclusive breastfeeding AND multivariate". The article review process can be seen in the search flow diagram in Figure 1.

There are 13 articles of observational studies, 595 of them are obtained from journal databases about the effects of exclusive breastfeeding on wasting in infants. A total of 572 articles were excluded due to duplication of articles, not observational studies, articles not in English, outcome not wasting, non-toddler subjects, interventions not exclusive breastfeeding, not multivariate analysis, not controlling confounding factors, and not fulfilling quantitative requirements.

Based on Figure 2, the inclusion particles came from 3 continents namely Asia, Africa and Europe. There are 4 studies from the Asian continent, namely 2 studies from Bangladesh and 2 studies from Vietnam and Palestine. There are 8 studies from the continent of Africa, namely 5 studies from Ethiopia and 3 other studies from the countries of Tanzania, Nigeria and Sudan. There is 1 study from continental Europe which originates from the country of Portugal.

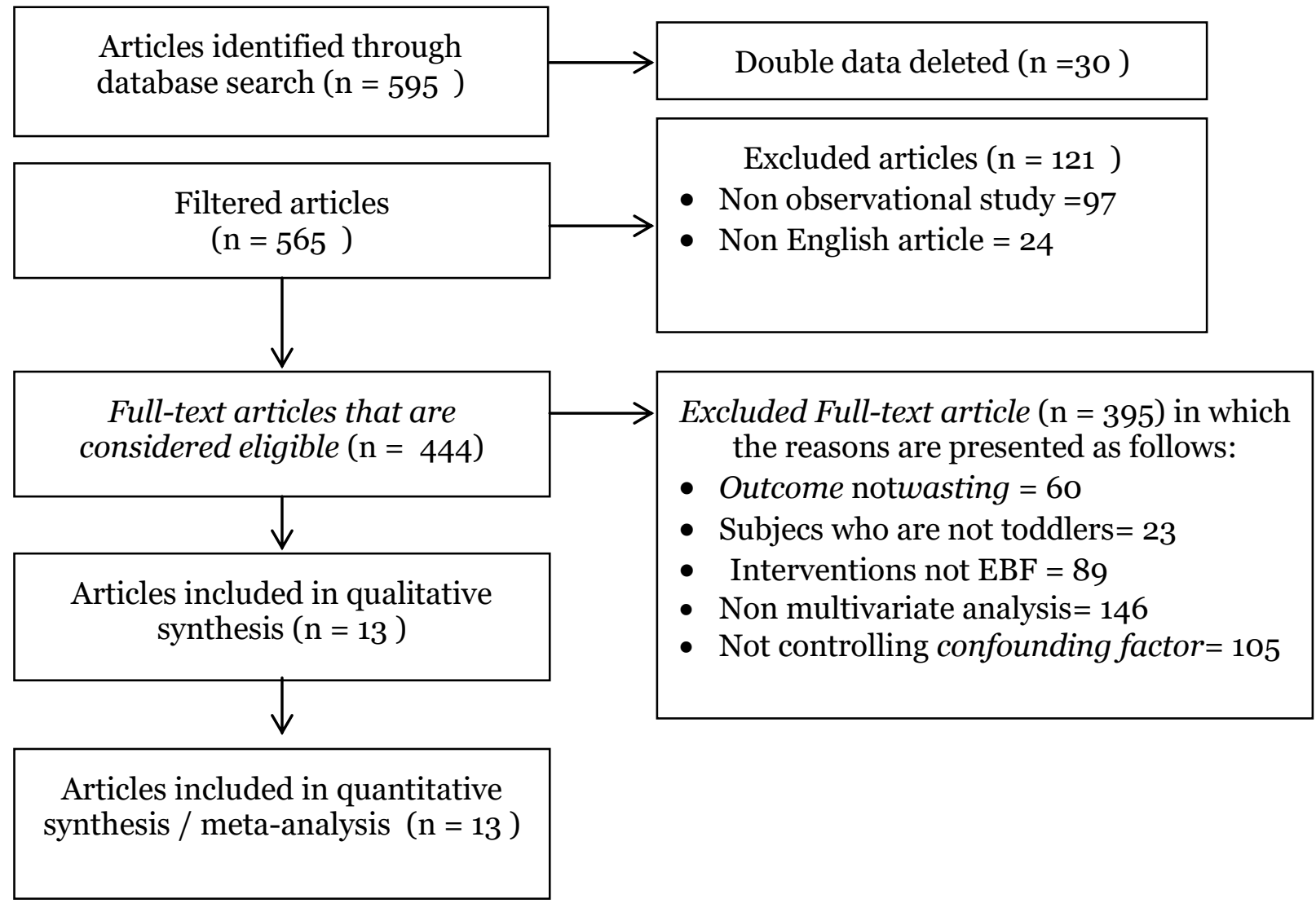

Figure 1. Review Flow Chart 


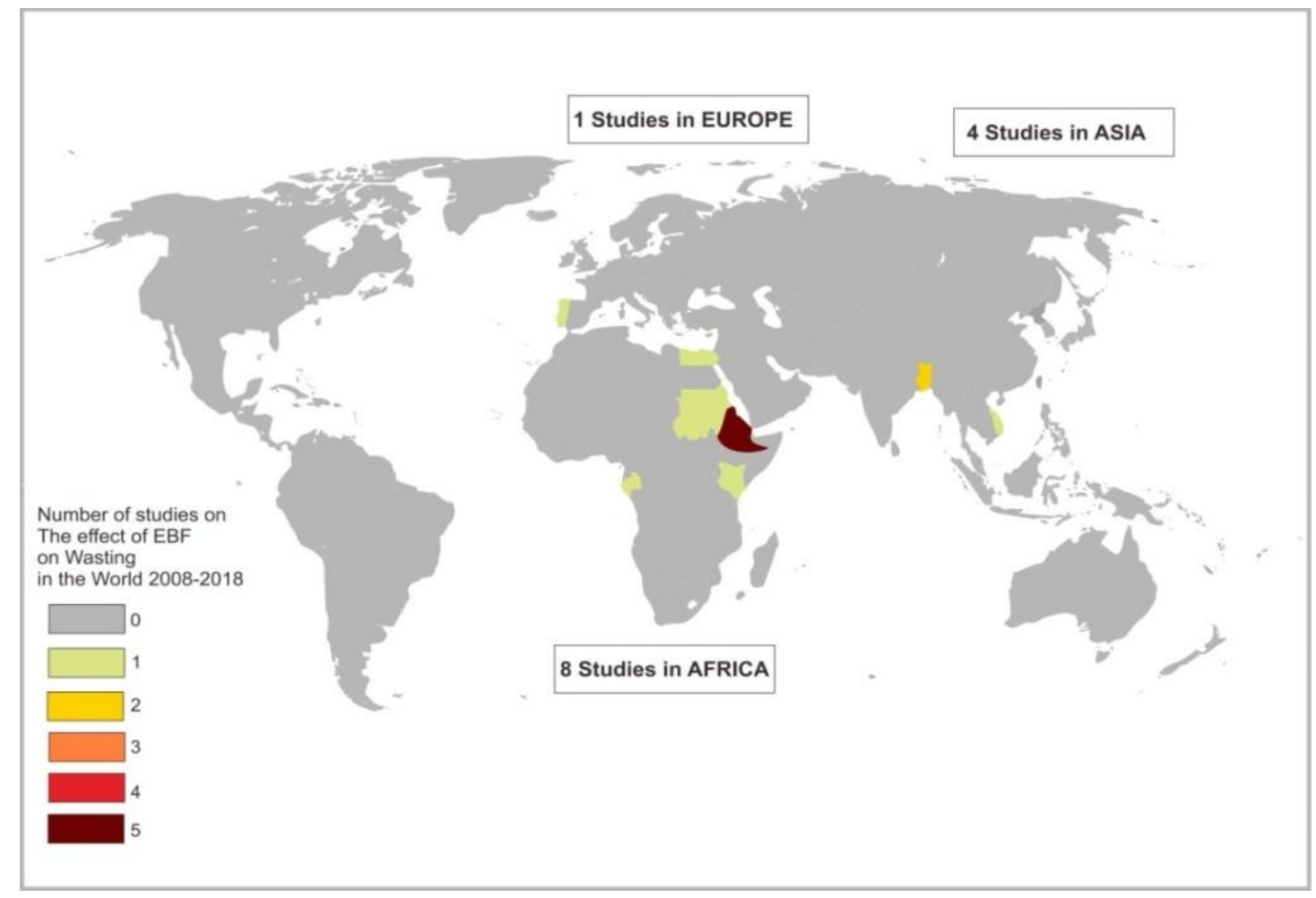

Figure 2. Overview of the Study Area

Based on Table 1 , there is 1 study from the State of Portugal in the Continent of Europe which is included in the classification of developed countries. There are 2 studies included in the classification of developing countries, namely research from
Vietnam on the Asian Continent and Tanzania on the African Continent. While the other 10 studies come from countries that are classified as lagging countries (underdeveloped/ least developed country).

Table 1. Country classification in wasting research based on world economic conditions (United Nations)

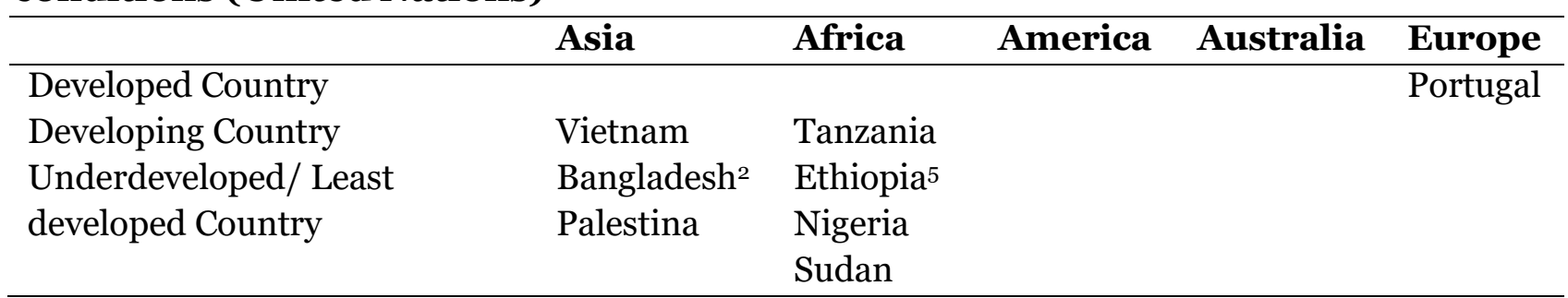

${ }^{2}$ There are two studies in a country

5There are five studies in a country

1. The effect of exclusive breastfeeding on wasting: cross-sectional meta-analysis study.

The investigation of articles through several databases found that there were six crosssectional study articles that had an addjust- ed odds ratio (AOR) about the effects of exclusive breastfeeding on wasting in children under five from a total of 595 articles found. The summary source article in the 6 articles is as follows: 
Table 2. Summary source of the effect of exclusive breastfeeding on wasting (cross-sectional study)

\begin{tabular}{|c|c|c|c|c|c|}
\hline \multirow[t]{2}{*}{ Author and Year } & \multirow[t]{2}{*}{ Country } & \multirow[t]{2}{*}{ Total Sample } & \multirow{2}{*}{$\begin{array}{c}\text { Age } \\
\text { (Month) }\end{array}$} & \multicolumn{2}{|c|}{$\begin{array}{c}\text { Exclusive } \\
\text { Breastfeeding }\end{array}$} \\
\hline & & & & AOR & $95 \% \mathrm{CI}$ \\
\hline Abebe et al. (2017) & Ethiopia & $\begin{array}{l}\text { Total: } 707 \\
\text { EBF: } 577 \\
\text { No EBF:130) }\end{array}$ & $6-59$ & 0.17 & $0.05-0.5$ \\
\hline Adeba et al.(2015) & Ethiopia & $\begin{array}{l}\text { Total: } 359 \\
\text { EBF: } 350 \\
\text { No EBF: } 9\end{array}$ & $6-59$ & 1.96 & $0.3-9.09$ \\
\hline $\begin{array}{l}\text { Agedew et al. } \\
(2016)\end{array}$ & Ethiopia & $\begin{array}{l}\text { Total: } 562 \\
\text { EBF: } 250 \\
\text { No EBF: } 312\end{array}$ & $6-23$ & 0.45 & $\begin{array}{l}0.25^{-} \\
0.83\end{array}$ \\
\hline Hien et al.(2008) & Vietnam & $\begin{array}{l}\text { Total: } 607 \\
\text { EBF: } 104 \\
\text { No EBF: } 503\end{array}$ & $6-59$ & 0.25 & $\begin{array}{l}0.07^{-} \\
0.92\end{array}$ \\
\hline Kejo et al. (2018) & Tanzania & $\begin{array}{l}\text { Total: } 436 \\
\text { EBF: } 70 \\
\text { No EBF::366 }\end{array}$ & $<36$ & 0.40 & $0.15^{-1.0}$ \\
\hline Valente (2016) & Portugal & $\begin{array}{l}\text { Total: } 1285 \\
\text { EBF: } 45 \\
\text { No EBF: } 1240\end{array}$ & $0-59$ & 0.56 & $0.21-1.45$ \\
\hline
\end{tabular}

Inclusion criteria: Full paper, cross-sectional design, multivariate analysis ofAdjusted Odds Ratio (AOR), EBF Intervention, toddler subject, outcome wasting/Weight for Height(WHZ) with Z score<2.AOR: Adjusted Odds Ratio.EBF: Exclusive Breastfeeding.

Based on the result of forest plot in Figure 3. Exclusive breastfeeding can prevent the incidence of wasting in toddlers byo.42 time $(\mathrm{OR}=0.42 ; 95 \% \mathrm{CI}=0.28$ up to 0.62$)$ and it was statistically significant $(\mathrm{p}<0.001)$. $\mathrm{I}^{2}=13 \%$ showed that study variation inforest plot was small orhomogeneous so that it used the fixed effect analysis model.

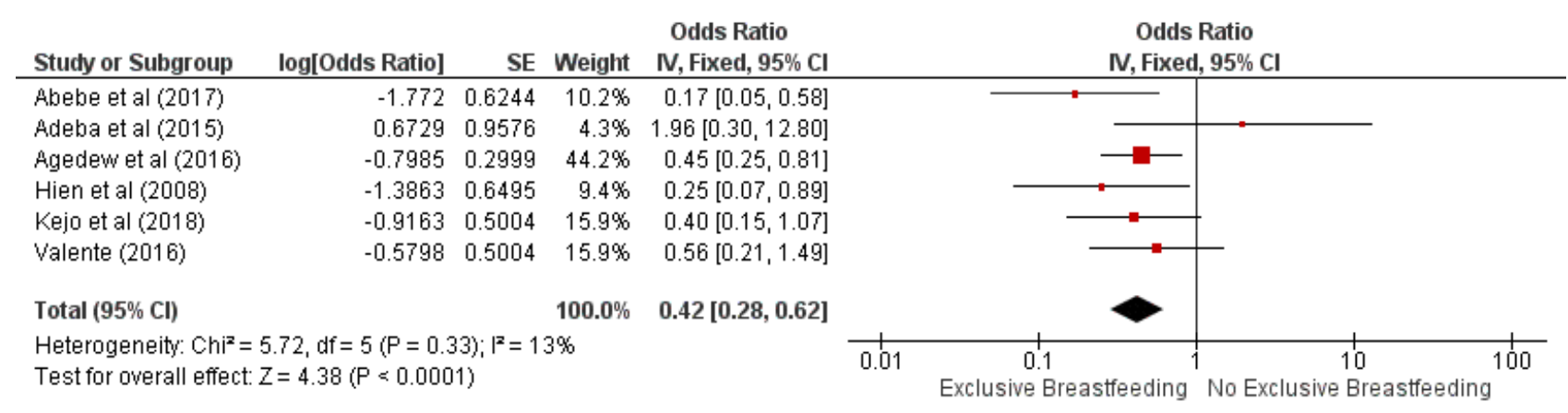

Figure 3. Forest plot of the effect of exclusive breastfeeding on wasting (cross-sectional study) 


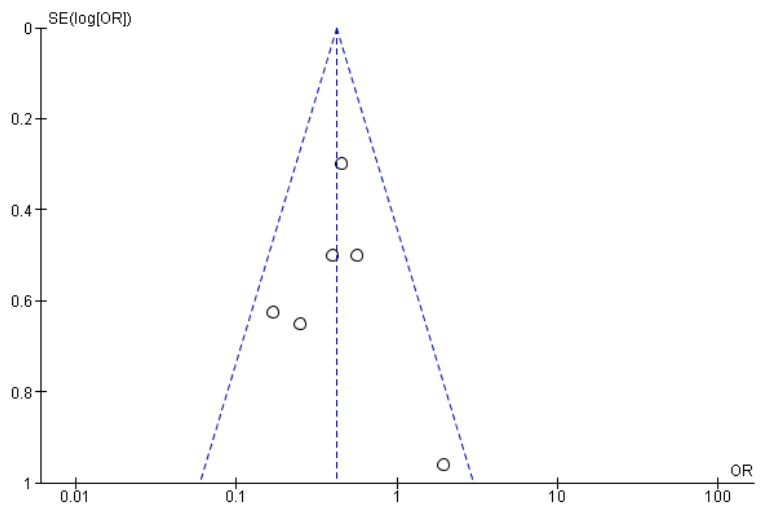

Figure 4. Funnel plot of the effect of exclusive breastfeeding on wasting (cross-sectional study)

In Figure 4, funnel plotof the effect of exclusive breastfeeding on wasting (crosssectional study) described symmetrical funnel-shaped graph facing down which indicated that there was no publication

Table 3.Summary Source ofthe Effect of Exclusive Breastfeeding on Wasting (Case-Control Study)

\begin{tabular}{|c|c|c|c|c|c|}
\hline \multirow[t]{2}{*}{ Author and Year } & \multirow[t]{2}{*}{ Country } & \multirow[t]{2}{*}{ Total Sample } & \multirow{2}{*}{$\begin{array}{c}\text { Age } \\
\text { (Month) }\end{array}$} & \multicolumn{2}{|c|}{$\begin{array}{c}\text { Exclusive } \\
\text { Breastfeeding }\end{array}$} \\
\hline & & & & AOR & $95 \% \mathrm{CI}$ \\
\hline Ayana et al. (2015) & Ethiopia & $\begin{array}{l}\text { Total: } 339 \\
\text { EBF: } 173 \\
\text { No EBF:166 }\end{array}$ & $6-59$ & 0.38 & $0.19-0.71$ \\
\hline Fuchs et al. (2014) & Bangladesh & $\begin{array}{l}\text { Total: } 449 \\
\text { EBF: } 228 \\
\text { No EBF:161 }\end{array}$ & $6-59$ & 0.37 & $0.17-0.81$ \\
\hline $\begin{array}{l}\text { Gazahegnet al. } \\
\text { (2017) }\end{array}$ & Sudan & $\begin{array}{l}\text { Total: } 281 \\
\text { EBF: } 105 \\
\text { No EBF:176 }\end{array}$ & $6-59$ & 0.27 & $\begin{array}{l}0.12- \\
0.60\end{array}$ \\
\hline Yassinet al. (2016) & Palestine & $\begin{array}{l}\text { Total: } 196 \\
\text { EBF: } 96 \\
\text { No EBF:10o }\end{array}$ & $6-59$ & 0.47 & $0.26-018$ \\
\hline
\end{tabular}

Inclusion criteria: Full paper, case-control design, multivariateanalysisof Adjusted Odds Ratio (AOR), EBF Intervention, toddler subject, outcome wasting/Weight for Height (WHZ) with Z score<-2.AOR: Adjusted Odds Ratio. EBF: Exclusive Breastfeeding.

Based on Figure 3.The result showed that toddlers who get exclusive breastfeeding can prevent the risk of wasting by 0.38 time $(\mathrm{OR}=0.38 ; 95 \% \mathrm{CI}=0.27$ hingga 0.54$)$ dan bias. In addition, the distance between the plots both left and right side was not too wide except for one plot with standard error $>0.8$, however, the plot was still in the symmetrical funnel graph.

2. The effect of exclusive breastfeeding on wasting: case-control metaanalysis study.

Of the 595 articles found through several journal databases, there were only 4 casecontrol studies articles of the effects of exclusive breastfeeding on wasting (weight for height) in toddlers with the Odds ratio which could control addjusted factors. Following is the table of source article summary: 
Wijiwinarsih et al./ The Effect of Exclusive Breastfeeding on Wasting

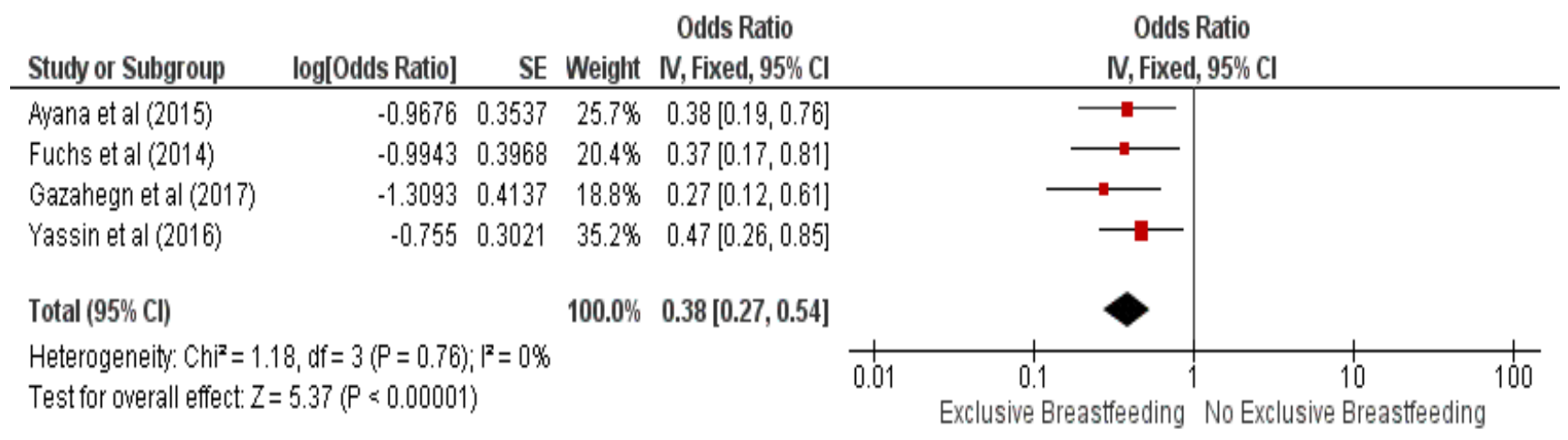

Figure 5. Forest plot ofthe effect of exclusive breastfeeding on wasting (case-control study)

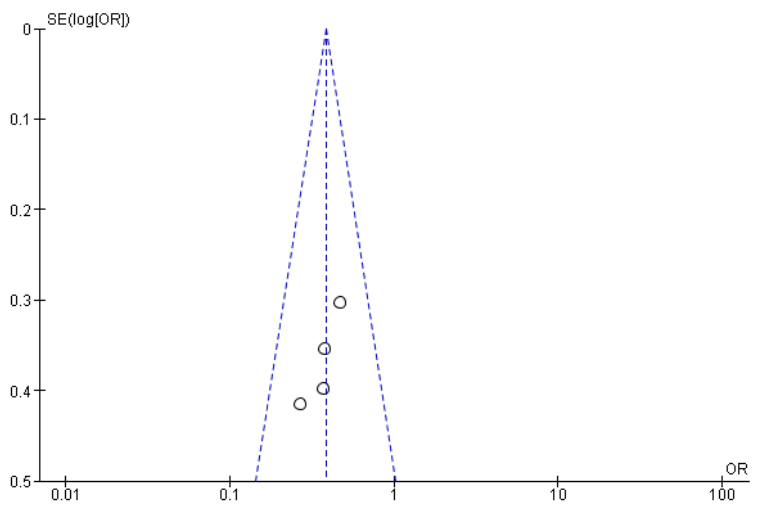

Figure 6. Funnel plot of the effect of exclusive breastfeeding on wasting (case-control study)

Figure 6 showed that funnel plotdid not indicate the publication bias because it was with the symmetrical left and right sides of the picture, in addition, there was a balance between the studies both the left and right sides of the funnel plot.

3. The effect of exclusive breastfeeding on wasting: cohort metaanalysis study

There were 3 articles about the effects of exclusive breastfeeding on wasting with a cohort study design. The value used in the data analysis was the addjusted odds ratio (AOR) that can control confounding factors. The summary of the source article is as follows:

a funnel-shaped graph facing downward

Table 4. Summary source of the effect of exclusive breastfeeding on wasting (cohort study)

\begin{tabular}{llllll}
\hline Author and Year & Country & Total Sample & \multicolumn{2}{c}{$\begin{array}{c}\text { Age } \\
\text { (Month) }\end{array}$} & \multicolumn{2}{c}{$\begin{array}{c}\text { Exclusive } \\
\text { Breastfeeding }\end{array}$} \\
\cline { 5 - 7 } & & & $6-59$ & 0.69 & 90. \\
\hline Egata et al. (2014) & Ethiopia & 2119 & & &
\end{tabular}

$\begin{array}{llllll}\text { Khan et al. (2017) } & \text { Bangladesh } & 1918 & 6 & 0.93 & 0.71-1.21\end{array}$

\begin{tabular}{|c|c|}
\hline Olusanya et al. & Nigeria \\
\hline
\end{tabular}
(2013)

Inclusion criteria: Full paper, cohortdesign, multivariate analysis of Adjusted Odds Ratio (AOR), EBF intervention, children under five, outcome wasting/weight for height (WHZ) with Z score <-2. AOR: Adjusted Odds Ratio. EBF: Exclusive Breastfeeding 
Based on data analysis in Figure 7 , the result showed that exclusive breastfeeding can prevent the incidence of wasting in toddlers by 0.75 time $(\mathrm{OR}=0.75 ; 95 \% \mathrm{CI}=$ 0.55 to 1.04 ) which was statistically non- significant $(\mathrm{p}=0.08)$. The study variation was quite large with the score of $\mathrm{I}^{2}=51 \%$. Therefore, it used a random effect analysis model.

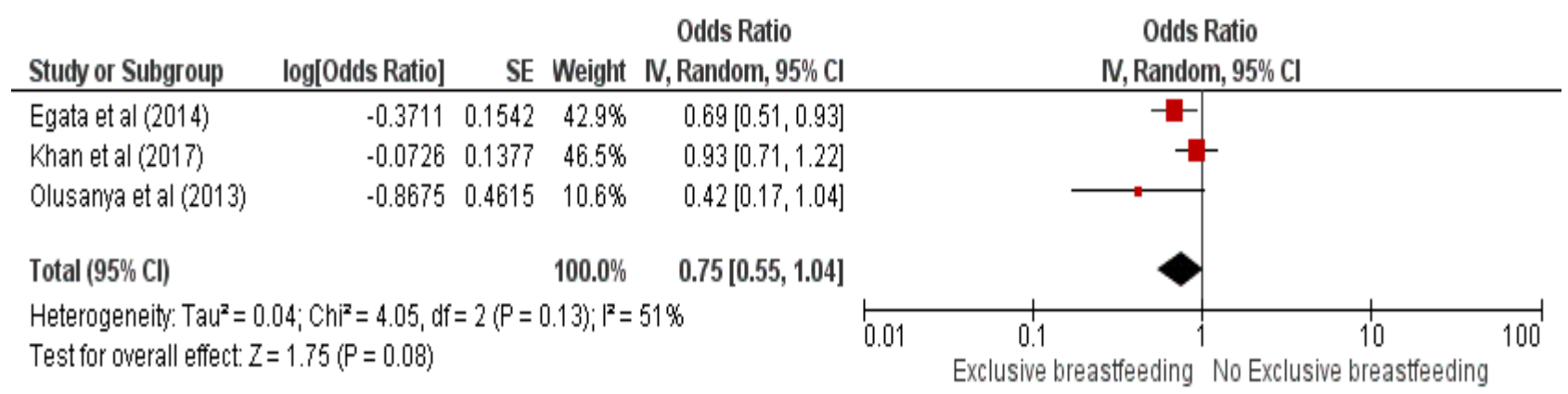

Figure 7. Forest plot of the effect of exclusive breastfeeding on wasting (cohort study)

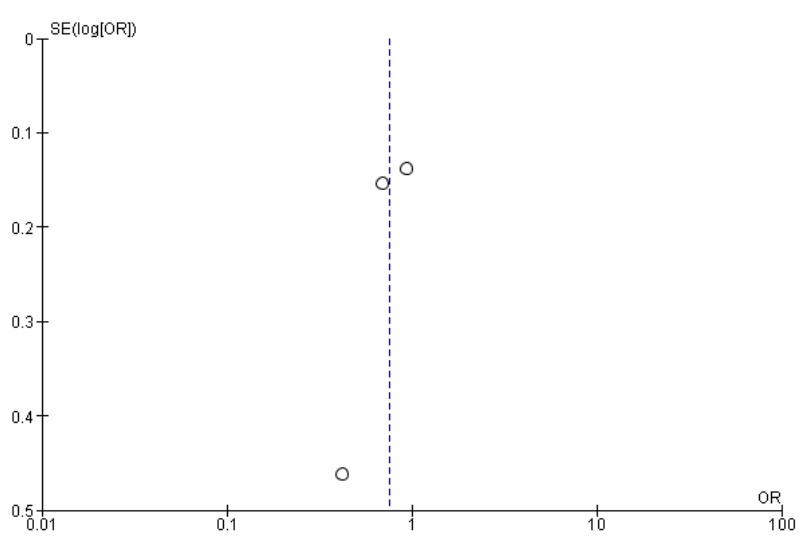

Figure 8. Funnel plot of the effect of exclusive breastfeeding on wasting (cohort study)

Based on Figure8, F funnel plotof the effect of exclusive breastfeeding on wasting (cohort study) indicated that there was a publication bias on findings because the left and right plots were not symmetrical. In the left plot, the plot distance was very wide, and the standard error scores were $<0.2$ and $>0.4$.

\section{DISCUSSION}

There were 13 articles from a total of 595 articles obtained from the journal search database. 13 articles came from Asia, Africa and Europe. Most articles found from the
African continent were in accordance with UNICEF data, WHO, World Bank Group Join Malnutrition Estimates, which reported that the prevalence of wasting in Africa reached 7.1 million people, which was one of the highest prevalence of wasting continent (WHO, 2018).

The origin country of the study was classified according to the conditions of the world economy according to the United Nations. The majority of countries from the study found to be classified as underdeveloped/Least developed countries. Least developed Country (LDC) was a low- 
income country that faced heavy structural barriers to sustainable development. They were very vulnerable to economic, environmental shocks and have low human resources (United nations, 2018). Least developed Country (LDC) was very closely related to wasting on toddlers because wasting would contribute to low human resources in the future.

Based on the results of the study, exclusive breastfeeding can prevent the risk of wasting on toddlers which in accordance with the results of the meta-analysis with a cross-sectional, case-control, and cohort design study. The results of the forest plot from the cross-sectional study showed that exclusive breastfeeding had a moderate size of relationship as a protective factor in preventing toddlers from wasting by 0.42 times $(\mathrm{OR}=0.42 ; 95 \% \mathrm{CI}=0.28-0.62)$ and it was statistically significant $(\mathrm{p}<0.001)$. The result of funnel plot did not indicate a publication bias in the study.

Similar to the results of the forest plot and funnel plot cross-sectional studies, the results of the forest plot from the casecontrol study showed that exclusive breastfeeding had a moderate relationship as a protective factor in preventing toddlers from wasting 0.38 by times $(\mathrm{OR}=0.38$; $95 \%$ $\mathrm{CI}=0.27-0.54)$ and it was statistically significant $(p<0.001)$. The result of funnel plot did not indicate a publication bias. This was in accordance with previous studies which reported that exclusive breastfeeding was a protective factor in preventing wasting in toddlers with the moderate strength of relationship (Asfaw et al., 2015; Woreda, 2016).

In contrast to the results of the crosssectional and case-control meta-analysis study, the results of forest plots from the cohort study showed that the exclusive breastfeeding had a weak relationship as a protective factor in preventing wasting in toddlers by 0.75 times which was statistically non-significant and there was publication bias $(\mathrm{OR}=0.75 ; 95 \% \mathrm{CI}=0.55$ to 1.04; $\mathrm{p}=0.080)$. This was because there were only few studies on the effects of exclusive breastfeeding on wasting in children under five which used a cohort study design.

The limitation of this study was that the research was only conducted in the last 10 years from 2008-2018 so that further researchers were expected to look for published articles in a wider period of time. In addition, the researchers only used 10 indexing databases in finding out published articles. The further researcher was expected to be able to expand the article searching area by adding indexing databases that have not been used.

\footnotetext{
REFERENCE

Abebe Z, Anlay DZ, Biadgo B, Kebede A, Melku T, Enawgaw B, Melku M (2017). High Prevalence of Undernutrition among Children in Gondar Town, Northwest Ethiopia: A Community-Based Cross-Sectional Study. International journal of pediatrics. Doi: $10.1155 / 2017 / 5367070$.

Aguayo VM, Badgaiyan N, Dzed L (2017). Determinants of child wasting in Bhutan. Insights from nationally representative data. Public Health Nutrition, 20(2): 315-324. DOI: 10$.1017 / \mathrm{S} 1368980016002111$.

AsfawM, Wondaferash M, Taha M, Dube L (2015). Prevalence of undernutrition and associated factors among children aged between six to fifty nine months in Bule Hora district, South Ethiopia. BMC public health. BioMed Central. 15: 41. Doi: 10.1186/s12889-015-1370-9.

BentleyA, Das S, Alcock G, More NS, PantvaidyaS, Osrin D (2015). Malnutrition
} 
and infant and young child feeding in informal settlements in Mumbai, India: findings from a census.Food Science and Nutrition. 3(3): 257-271. Doi: $10.1002 /$ fsn3.214.

BlackRE, Allen LH, Bhutta ZA, Caulfield LE, Onis MD, Ezzati M (2008). Maternal and child undernutrition: global and regional exposures and health consequences.Lancet (London, England). Elsevier: 243-60. DOI: 10.1016/So140-6736(07)61690.

Black RE, Victora CG, Walker SP, Bhutta ZA, Christian P, Onis MD (2013). Maternal and child undernutrition and overweight in low-income and middle-income countries. Lancet (London, England). Elsevier: 427-451. Doi: 10.1016/So140-6736(13)60937X.

Briend A, Khara, T, Dolan, C (2015). Wasting and stunting-similarities and differences: Policy and programmatic implications: 36(1). Doi: 10.1177/$15648265150361 \mathrm{~S} 103$.

FekaduY, Mesfin A, Haile D (2015). Factors associated with nutritional status of infants and young children in Somali Region, Ethiopia: a cross- sectional study. BMC Public Health. BMC Public Health. 15(1): 846. Doi: 10.1186/s12889-015-2190-7.

GautamS, Ruchal S, Acharya D, Khadka, Gautam V, Sigh JK (2017) Effect of Maternal Socio-demographic Factors and Child Feeding Practice on Wasting Among Under Five Years Children in Slum Area of Rupandehi District in Nepal.JNMA; journal of the Nepal Medical Association. 56-
(206): 256-261. Available at: http://www.ncbi.nlm.nih.gov/pubmed/28 746325 (Accessed: 24 May 2018).

Tariku B, Mulugenta A, Tsadik M, Azene G (2016). Nearly half of preschool children are stunted in Dembia district. Northwest Ethiopia: a community based cross-sectional study. Archives of public health Archives belges de sante publique. BioMed Central: 13 . DOI: 10.1186/s13690-016-0126-z.

UNICEF (2018).Makan Bayi dan Anak Muda. Available at: https://data.unicef.org/topic/nutrition/infant-andyoung-child-feeding/\# (Accessed: 19 May 2018).

United nations (2018) Least Developed Countries (LDCs)Economic Analysis and amp; Policy Division. Available at: https://www.un.org/development/desa/dpad/least-developed-countrycategory.html (Accessed: 5 December 2018).

WHO (2018) WHOJoint child malnutrition estimates-Levels and trends (2018 edition). WHO. World Health Organization. Available at: https://www.who.int/nutgrowthdb/estimates2017/ en/ (Accessed: 4 December 2018).

WHO (2018) Malnutrition. Available at: http://www.who.int/en/news-room/factsheets/detail/malnutrition (Accessed: 5 June 2018).

Woreda A, Demissie DB, Belachew T (2016). Predictors of Acute Malnutrition Among 6-23 Months Children. Journal of Health, Medicine and Nursing: 119-129. 